\title{
Stamping formability of pure titanium sheets
}

\author{
Fuh-Kuo Chen*, Kuan-Hua Chiu \\ Department of Mechanical Engineering, National Taiwan University, Taipei 10764, Taiwan, ROC
}

Received 20 October 2003; received in revised form 12 April 2005; accepted 4 May 2005

\begin{abstract}
Because of hexagonal close-packed (HCP) crystal structures, commercially pure titanium (CP Ti) shows low ductility at room temperature, and requires thermal activation to increase its ductility and formability. In the present study, the formability of $\mathrm{CP}$ Ti sheets at various temperatures was studied by the experimental approach. Tensile tests were first conducted to investigate the mechanical behavior of $\mathrm{CP}$ Ti sheets at various temperatures. Forming limit tests, V-bend tests, and cup drawing tests were also performed to examine the stamping formability of CP Ti sheets at various temperatures. The experimental results indicate that CP Ti sheets could be formed into shallow components at room temperature, although the formability is limited in cold forming. In addition, the results obtained from the V-bend tests reveal that springback can be reduced at elevated forming temperatures. The experimental results obtained in the present study can be of help to the die design of stamping CP Ti sheets.
\end{abstract}

(C) 2005 Elsevier B.V. All rights reserved.

Keywords: Pure titanium sheet; Formability; Forming limit; V-bend; Springback

\section{Introduction}

Due to its lightweight and high specific strength, commercially pure titanium (CP Ti) has been a potential material for structural components, and attracts much attention from the electronics industry recently. The principal manufacturing process of $\mathrm{CP}$ Ti has been press forming because of its competitive productivity and superior performance. Among the fabrication processes of press forming, stamping of CP Ti sheets is especially important for the production of thin-walled structural components used in the electronics products, such as the cover cases of notebook, mobile phone, etc. The CP Ti sheet usually exhibits limited ductility at room temperature because of its hexagonal close-packed (HCP) structure. Although the formability can be improved at elevated temperatures, a manufacturing process at room temperature is always desired for the cost-effective reason. However, most research of CP Ti is focused on microstructure [1-4], and the literature regarding formability of stamping CP Ti sheets is not profound.

\footnotetext{
* Corresponding author. Tel.: +886 2 33662701; fax: +8862 3631755.

E-mail address: fkchen@ccms.ntu.edu.tw (F.-K. Chen).
}

In the present study, the formability of stamping $\mathrm{CP} \mathrm{Ti}$ sheets was investigated using the experimental approach. The mechanical properties of $\mathrm{CP}$ Ti sheets at various temperatures ranging from room temperature to $300^{\circ} \mathrm{C}$ were obtained from experimental results. In addition, the important forming characteristics of CP Ti sheets, such as forming limit, springback, and limiting drawing ratio, were also examined by experiments.

\section{Mechanical properties tests at various temperatures}

The stress-strain relations are the fundamental information for the study of formability of a sheet metal. As mentioned above, the formability of CP Ti sheets is limited at room temperature and can be improved at elevated forming temperatures. In order to examine the variety of mechanical properties of CP Ti sheets at different temperatures, tensile tests were performed at various temperatures ranging from room temperature to $300^{\circ} \mathrm{C}$ and under different strain rates of $0.1,0.01,0.001$, and $0.0001 / \mathrm{s}$, respectively. The tensile test specimens made of JIS Grade 1 CP Ti sheets of $0.5 \mathrm{~mm}$ 


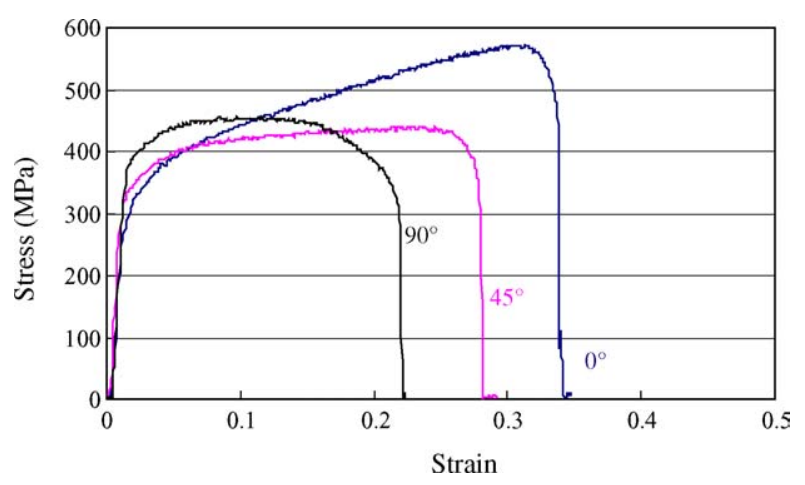

Fig. 1. True stress-strain relations at room temperature obtained from specimens in the three directions.

thickness were prepared according to the ASTM standards. The specimens were cut along planes coinciding with the rolling direction $\left(0^{\circ}\right)$, and at angles of $45^{\circ}$ and $90^{\circ}$ to the rolling direction. The specimens were wire cut to avoid burrs along the edge.

The tensile tests were conducted using an MTS 810 test machine. For tests at elevated temperatures, a heating furnace was mounted on the MTS 810 test machine. The specimens were heated to 100,200 , and $300^{\circ} \mathrm{C}$ before the tensile tests were performed. During tests, the temperature of specimen was kept constant until the specimen was stretched to failure.

In the present study, the engineering stress-strain relations were first obtained from the experimental data and then were converted into the true stress-strain relations according to $\sigma=\sigma_{0}(1+e)$ and $\varepsilon=\ln (1+e)$, where $\sigma$ and $\varepsilon$ were true stress and true strain, $\sigma_{0}$ and $e$ were engineering stress, and engineering strain, respectively. The true stress-strain relations for CP Ti sheets at room temperature obtained from specimens cut in the three different orientations are shown in Fig. 1. The anisotropic behavior is observed in Fig. 1. It is seen in Fig. 1 that the $0^{\circ}$ specimen has a higher yield strength and a larger elongation than the specimens in the other two directions, the difference in elongation being more significant. It is also observed that the $0^{\circ}$ specimen displays a significant work-hardening property among the specimens in the three directions. These results are consistent with those obtained by Ishiyama et al. [5]. They found that the slip deformation occurs in both the $0^{\circ}$ and $90^{\circ}$ directions in the beginning stage of the test. During further deformation stage, the twinning deformation increases faster in the $0^{\circ}$ direction and produces higher resistance against the slip of dislocations, resulting in larger values in yield strength, work hardening, and elongation. The average yield stress and elongation of the $\mathrm{CP}$ $\mathrm{Ti}$ sheet at room temperature are about $352 \mathrm{MPa}$ and $28 \%$, respectively. Though the values of yield stress and elongation of the CP Ti sheet at room temperature are not favorable in a deep drawing process compared to those of carbon steels, they are feasible for stamping of relatively shallow products from the formability point of view.

Fig. 2 shows the original and deformed specimens in the three directions. It is noticed in Fig. 2 that the $0^{\circ}$ specimen

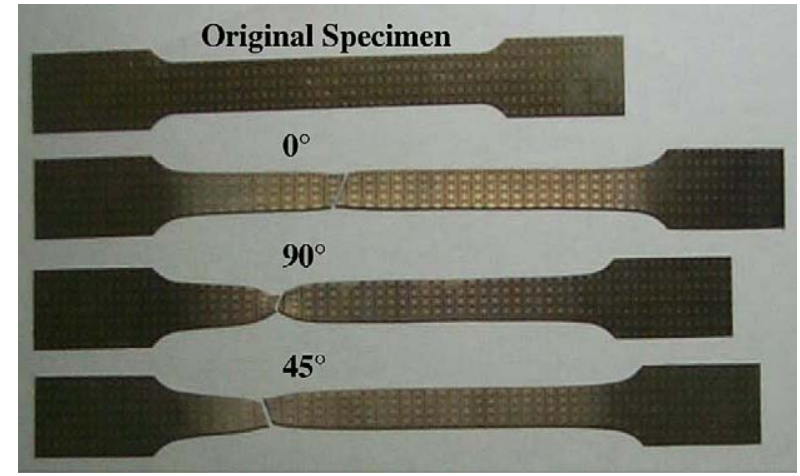

Fig. 2. Original and deformed specimens in the three directions.

undergoes uniform deformation before fracture, while the $90^{\circ}$ specimen displays an obvious necking, and the deformation mode of $45^{\circ}$ specimen lies between those of other two modes.

In order to examine the effect of strain-rate on the deformation of CP Ti sheets, the tensile tests were also performed at room temperature under different ram speeds, resulting in different strain-rates of $0.1,0.01,0.001$, and 0.0001 , respectively. The true stress-strain relations at various strain-rates for the $0^{\circ}$ specimen are shown in Fig. 3. A significant drop in the stress-strain curves from strain-rate 0.1 to 0.001 is noticed in Fig. 3, and the stress-strain curves become close to each other afterwards. The same trends are also observed in the tensile tests for the $45^{\circ}$ and $90^{\circ}$ specimens. It indicates that a stable stress-strain relations for $\mathrm{CP}$ Ti sheets can be obtained under the strain-rates smaller than 0.001 .

The true stress-strain relations of $\mathrm{CP} \mathrm{Ti}$ sheets at various temperatures ranging from room temperature to $300^{\circ} \mathrm{C}$ for the specimen of $0^{\circ}$ direction are shown in Fig. 4. The relations shown in Fig. 4 are obtained from the tests performed at strain-rate of 0.001 . It is seen in Fig. 4 that the $\mathrm{CP}$ Ti sheet exhibits better formability at elevated temperatures. The stress-strain curves get lower proportionally to the increase of testing temperature. It is to be noted in Fig. 4 that the elongation of the specimen does not increase from room temperature to $100{ }^{\circ} \mathrm{C}$ as expected, on the contrary, the elongation gets smaller when the specimen is heated up to $100^{\circ} \mathrm{C}$. However, the elongation becomes larger at testing

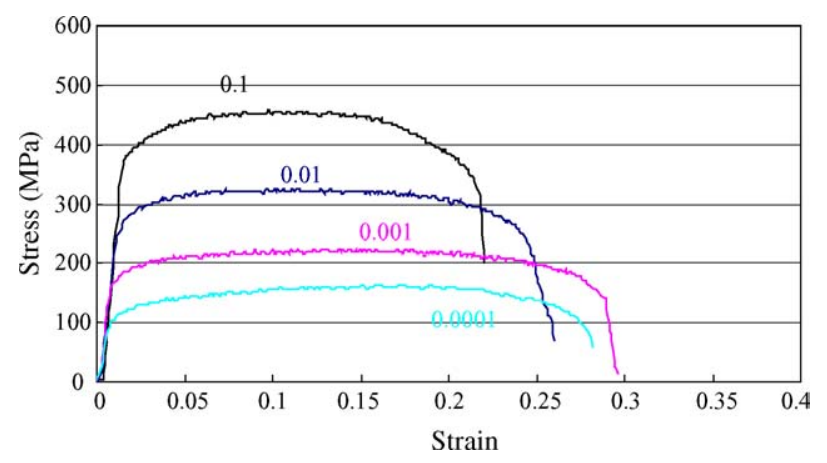

Fig. 3. True stress-strain relations at various strain-rates $(1 / \mathrm{s})$ for $0^{\circ}$ specimen at room temperature. 


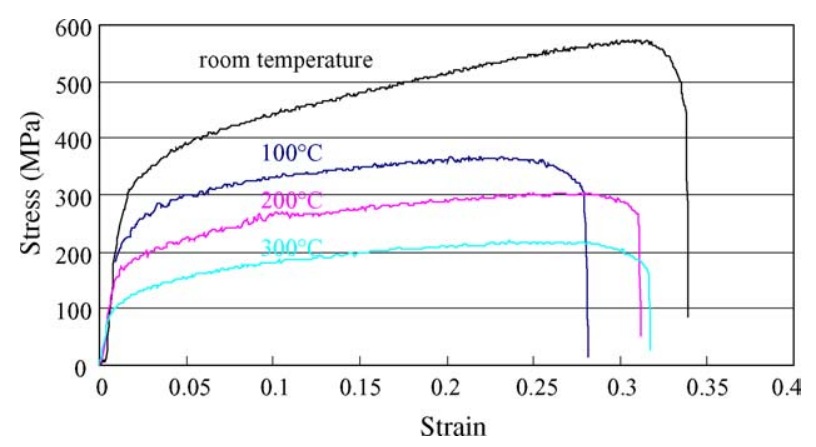

Fig. 4. True stress-strain relations at various temperatures for $0^{\circ}$ specimen.

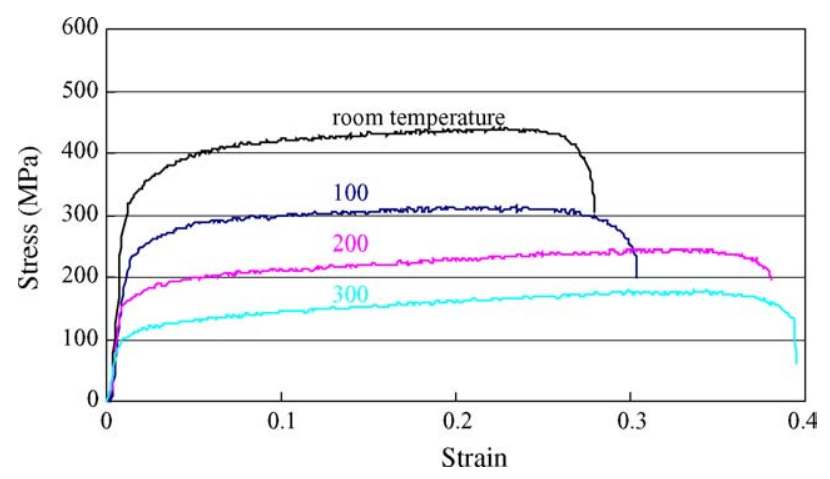

Fig. 5. True stress-strain relations at various temperatures for $45^{\circ}$ specimen.

temperatures higher than $100^{\circ} \mathrm{C}$. The greater elongation at room temperature is quite unusual. But this phenomenon only happens to the $0^{\circ}$ specimen. For the $45^{\circ}$ and $90^{\circ}$ specimens, the elongation continuously increases as the testing temperature gets elevated, as shown in Figs. 5 and 6, respectively. The greater elongation at room temperature occurred in the $0^{\circ}$ specimen might be due to the fast increase of the twinning deformation in the $0^{\circ}$ direction at room temperature, producing higher resistance against the slip of dislocations, and resulting in a larger elongation.

Another index of anisotropy is the plastic strain ratio, i.e. $r$-value, which is defined as the ratio of plastic strain in the transverse direction to that in the thickness direction in a uniaxial tensile test. In the present study, the $r$-value was obtained from the tensile tests for specimens of $0^{\circ}, 45^{\circ}$, and

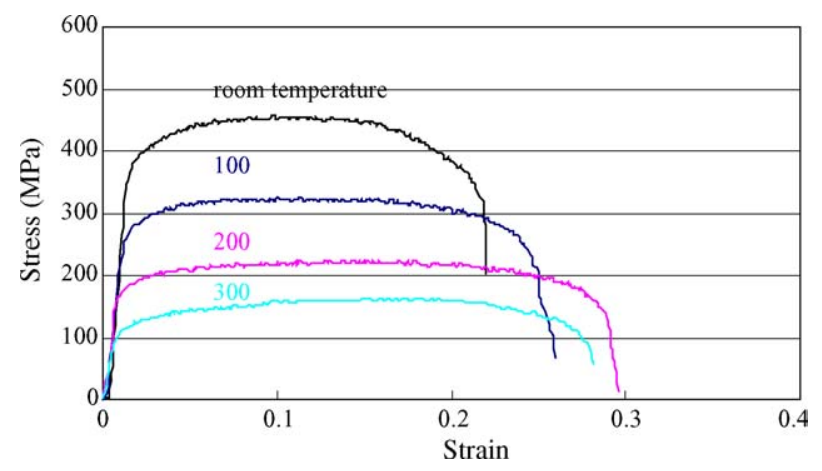

Fig. 6. True stress-strain relations at various temperatures for $90^{\circ}$ specimen. $90^{\circ}$ directions at room temperature. The $r$-values measured from specimens stretched to $20 \%$ are $4.2,2.2$, and 2.1 for the $0^{\circ}, 45^{\circ}$, and $90^{\circ}$ specimens, respectively. Since a higher $r$ value indicates better drawability, it shows that $\mathrm{CP}$ Ti sheets exhibit better deep drawing quality in the rolling direction than the other two directions. Also the anisotropy of CP Ti sheets was confirmed again from the significant difference of $r$-values.

\section{Stamping formability of CP Ti sheets}

In addition to the basic mechanical properties, the stamping formability of $\mathrm{CP} \mathrm{Ti}$ sheets was also examined. In the present study, the forming limit tests at room temperature, and the V-bend tests and circular cup drawing tests at various temperatures were performed. The test results were discussed relating to the forming properties of $\mathrm{CP}$ Ti sheets in a stamping process.

\subsection{Forming limit tests}

Since Keeler and Backofen [6] introduced the concept of forming limit diagram (FLD) in 1963, it has been a widely accepted criterion for the fracture prediction in the sheetmetal forming. To determine an FLD, stretching tests were performed for sheet-metal specimens of different widths using a semi-spherical punch. The specimens were first electrochemically etched with circular grids that would be deformed into ellipses after being stretched. The engineering strains measured along the major- and minor-axes of the ellipse are termed the major- and minor-strain, respectively. They are also the principal strains on the plane where the strains are measured.

In the present study, rectangular specimens having the same length of $100 \mathrm{~mm}$, but with different widths ranging from 10 to $100 \mathrm{~mm}$ in an increment of $10 \mathrm{~mm}$, were tested. Similar to tensile tests, the CP Ti sheet was cut at three orientations to the rolling direction, i.e., $0^{\circ}, 45^{\circ}$, and $90^{\circ}$, for each size of specimen. During the tests, specimens clamped at periphery were stretched to failure over a $78 \mathrm{~mm}$ semispherical punch. The engineering major- and minor-strains measured in the location closest to the fracture for each specimen were recorded. The major- and minor-strains were plotted against one another with the major strain as the ordinate, and the curve fitted into the strain-points was defined as the forming limit curve. The diagram showing this forming limit curve is called the forming limit diagram. The FLD is a very useful criterion for the prediction of the occurrence of fracture in a stamping process.

According to the previous analysis, the CP Ti sheet could be formed at room temperature. In order to further confirm its feasibility, the forming limit tests were performed at room temperature. Fig. 7 shows the forming limit curve obtained from the test results. It is seen in Fig. 7 that the major strain at the lowest point of the curve, which is also the plane strain 


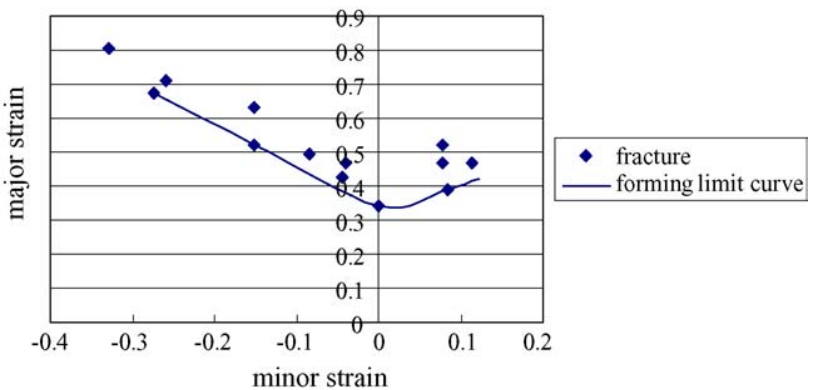

Fig. 7. Forming limit curve at room temperature.

deformation mode, is 0.34 . Compared with cold-rolled steels or stainless steels, this value is a little lower. However, for stamping of shallow products, the forming limit curve shown in Fig. 7 indicates a greater possibility of forming of $\mathrm{CP} \mathrm{Ti}$ sheets at room temperature. This makes it possible to manufacture electronics components at room temperature using CP Ti sheets.

\subsection{V-bend tests}

Since CP Ti has a lower value of elastic modulus than that of steel, springback could be much significant in a bending process. In the present study, the V-bend tests were performed to examine the springback property of $\mathrm{CP}$ Ti sheets at various forming temperatures. The tooling used in the V-bend tests is shown in Fig. 8. It can be seen in Fig. 8 that the lower die has an opening angle of $90^{\circ}$. In order to study the effect of punch radius on springback, the tooling sets with punch radii from 0.5 to $5.0 \mathrm{~mm}$, in an increment of $0.5 \mathrm{~mm}$, were prepared. The CP Ti sheet with a thickness of $0.5 \mathrm{~mm}$, a length of $60 \mathrm{~mm}$, and a width of $15 \mathrm{~mm}$ was used as specimens. For tests at elevated temperatures, both tooling and specimens were enclosed in a heating furnace. No lubricant was used in the V-bend test since the frictional condition has an insignificant effect on the springback occurred in the V-bend test. The bending tests were conducted at room temperature, 100,200 , and $300^{\circ} \mathrm{C}$, respectively. After bending tests, the

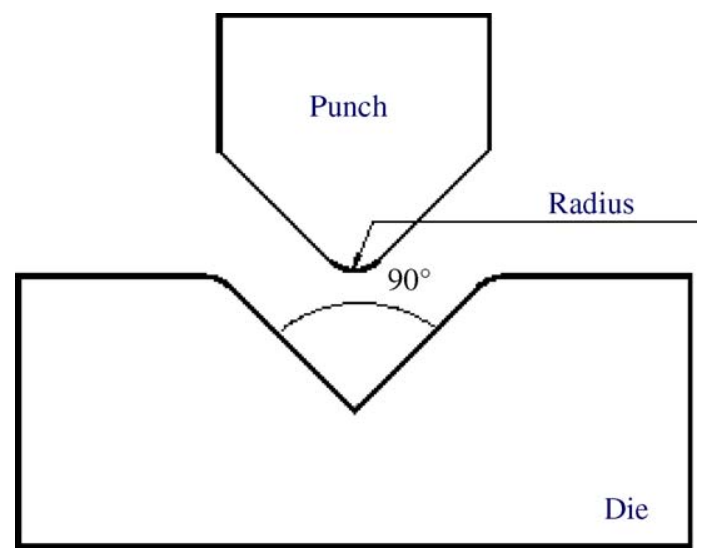

Fig. 8. Tooling used in the V-bend tests.

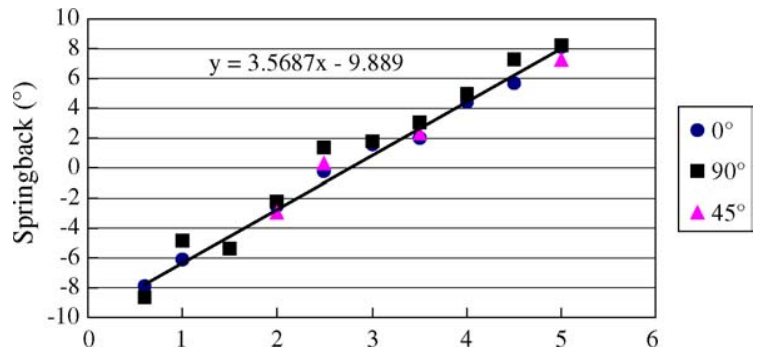

Fig. 9. Relations between springback and punch radius at room temperature for specimens of three directions.

angles of bent specimens were measured by a CMM, and the springback angles were calculated.

Figs. 9 and 10 show the relationships between springback and punch radius at room temperature and $300^{\circ} \mathrm{C}$, respectively. It is seen in both figures that the springback decreases for smaller punch radii regardless of temperature change. The smaller punch radius causes larger plastic deformation at the bend, and hence reduces the effect of springback. It is also noted in both Figs. 9 and 10 that negative values of springback occur for smaller punch radii. This is because that the sheet on the straight sides of V-shape is deformed into an arc at the beginning of bending process, and the load applied to flatten the arc at the end of bending process results in a complex stress distribution that causes a negative value of springback [7]. Comparing both figures, it is observed that

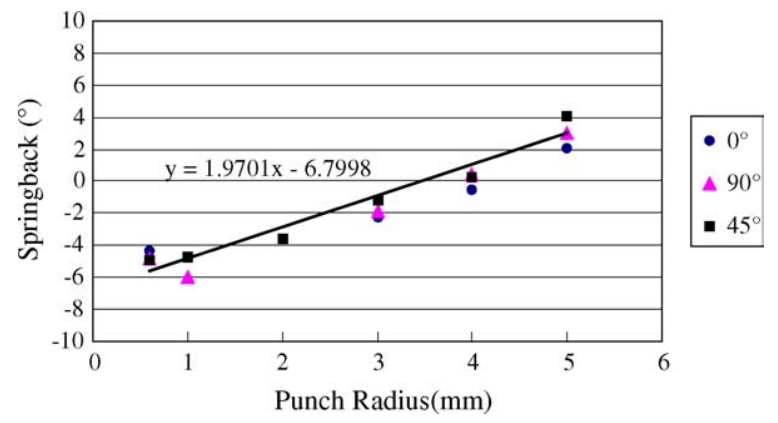

Fig. 10. Relations between springback and punch radius at $300^{\circ} \mathrm{C}$ for specimens of three directions.
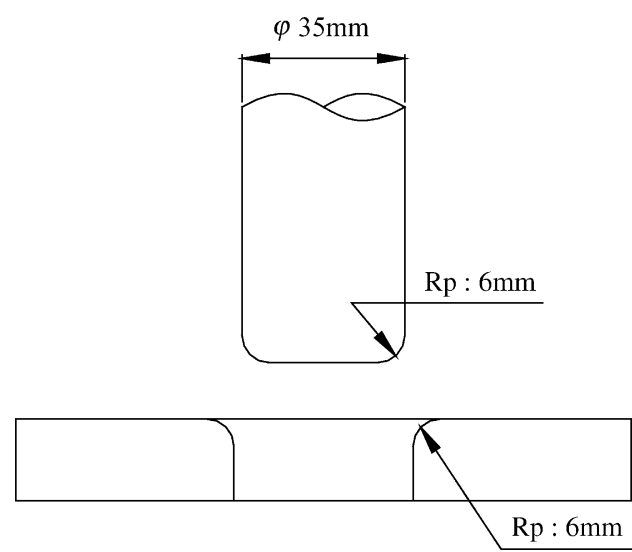

Fig. 11. Punch and die used in circular cup drawing tests. 


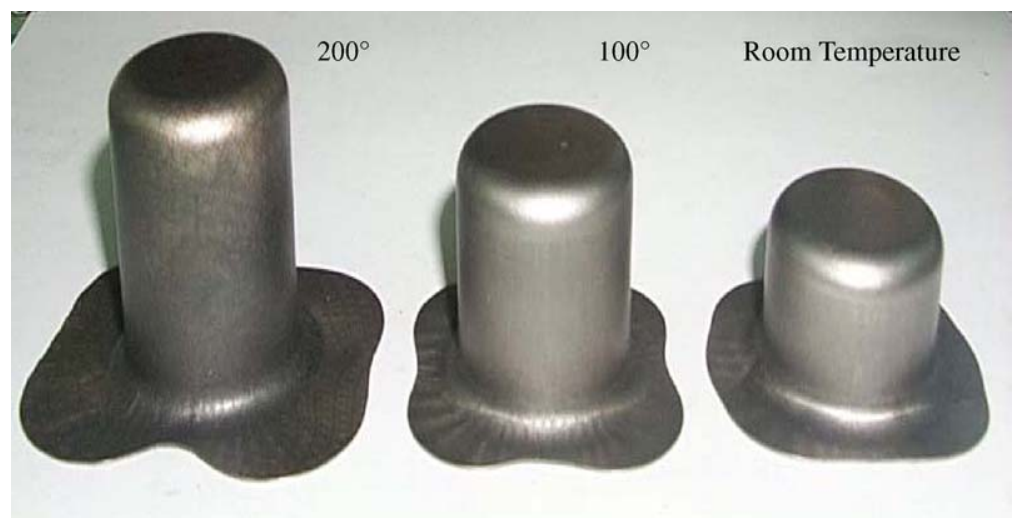

Fig. 12. Drawn cups at various forming temperatures.

springback decreases as the forming temperature increases regardless of the dimension of punch radius. It indicates that CP Ti sheets not only have better formability but also experience less springback at higher forming temperatures. It is known that springback is affected by both the elastic modulus and the yield stress of the material. Since the elastic modulus does not vary too much with the change of temperature, and the yield stress of CP Ti sheets decreases with the increase of temperature, the decrease of springback at higher forming temperatures is due to the lower yield stress of $\mathrm{CP} \mathrm{Ti}$ at elevated temperatures.

\subsection{Circular cup drawing tests}

The limiting drawing ratio (LDR), which is defined as the ratio of the largest diameter of circular blank (Do) to the punch diameter (Dp) in a successful circular cup drawing process, is a popular index used to describe the formability of sheet metals. A larger value of LDR implies a larger drawing depth, that is, a better formability. In the present study, the punch and die shown in Fig. 11 were used for the circular cup drawing tests. Tests were performed at room temperature, 100 , and $200{ }^{\circ} \mathrm{C}$, respectively. The heating apparatus used in the tensile tests was adopted for the tests at elevated temperatures. In order to obtain a successful drawing process, the blank size and blank-holder force were adaptively adjusted to eliminate the defects such as fracture and wrinkle. If the fracture appeared in a drawing test, the blank-holder force would be adjusted to a smaller value until the fracture was eliminated without the occurrence of wrinkles. When the adjustment of blank-holder force failed to eliminate the fracture, an attempt of reducing the blank size would be tried simultaneously to avoid the fracture. A reverse methodology could be adopted to suppress the occurrence of wrinkles in a drawing test. However, in an LDR test, the blank size is also acting as a parameter to determine the value of LDR in addition to the use of the above adjustment. Since the punch diameter is $35 \mathrm{~mm}$, the blank diameter is increased in an increment of $3.5 \mathrm{~mm}$ from $70 \mathrm{~mm}$ to the largest possible diameter for the convenience of calculating the values of
Table 1

Test results of circular cup drawing

\begin{tabular}{lccll}
\hline Temperature & $\begin{array}{l}\text { Blank diameter } \\
(\mathrm{mm})\end{array}$ & LDR & $\begin{array}{l}\text { Blank-holder } \\
\text { force }(\mathrm{kN})\end{array}$ & $\begin{array}{l}\text { Drawing } \\
\text { depth }(\mathrm{mm})\end{array}$ \\
\hline Room temperature & 77 & 2.2 & 2.75 & 20 \\
$100^{\circ} \mathrm{C}$ & 84 & 2.4 & 3.5 & 29 \\
$200^{\circ} \mathrm{C}$ & 101.5 & 2.9 & 4.0 & 40 \\
\hline
\end{tabular}

LDR. $\mathrm{MoS}_{2}$ was used as lubricant in all circular cup drawing tests conducted in the present study, and the drawing speed is $0.2 \mathrm{~mm} / \mathrm{s}$.

Fig. 12 shows the drawn cups at various temperatures. It is clearly seen in Fig. 12 that the drawing depth increases as the increase of forming temperature. It is also to be noted in this figure that the earing shapes of the drawn cup formed at various temperature are quite different. The earing phenomenon becomes significant at higher forming temperatures. The values of LDR, drawing depth, and related process parameters are listed in Table 1 for the tests conducted at various temperatures. It is noticed in Table 1 that all values increase as the forming temperature increases. However, the increase of LDR and drawing depth is not so significant in the range from room temperature to $100{ }^{\circ} \mathrm{C}$, but gets larger from 100 to $200{ }^{\circ} \mathrm{C}$. It is also noted in Table 1 that a larger blank-holder force is required for the larger blank size to be successfully drawn at a higher temperature. The value of LDR of CP Ti sheets is 2.2 at room temperature, which is comparable to that of carbon steels, indicating that stamping of CP Ti sheets at room temperature is feasible.

\section{Concluding remarks}

The formability of stamping CP Ti sheets at various forming temperatures was investigated in the present study by conducting various experiments. The mechanical properties of the CP Ti sheet at various temperatures were first examined, and the stress-strain relations obtained from the experiments indicate that the $\mathrm{CP} \mathrm{Ti}$ sheet has a higher yield stress and 
a smaller elongation at room temperature, but proportionally decreases in yield stress and increases in elongation when the sheet is heated to an elevated temperature up to $300^{\circ} \mathrm{C}$. It is to be noted that the stress-strain relations obtained from the tensile tests at room temperature indicate that the CP Ti sheet could be formed into shallow components at room temperature, although the yield stress is a little higher. The forming limit diagram of the $\mathrm{CP}$ Ti sheet obtained at room temperature is not so high as those of cold-rolled steels, but the minimum major strain of 0.34 also provides an optimum possibility for the CP Ti sheet to be formed at room temperature. The circular cup drawing tests reveal that the $\mathrm{CP}$ Ti sheet has an LDR value of 2.2 at room temperature, and a successfully drawn cup with a depth of $20 \mathrm{~mm}$ confirms that the $\mathrm{CP} \mathrm{Ti}$ sheet can be formed into shallow components at room temperature. However, the earing phenomenon displayed in the drawn circular cups indicates that the CP Ti sheet bears significant anisotropy in plane that could also affect the formability of drawing deep cups.

The strain-rate effect on the stress-strain relations at room temperature was also investigated. The experimental results show that the stress-strain relations become stable when the strain-rate is smaller than 0.001. In the V-bend tests, the experimental results reveal an important information that springback can be reduced at elevated forming temperatures. Also springback could be reduced if a smaller punch radius is used to form the parts. The experimental results obtained in the present study provide the fundamentals for the stamping die design of forming CP Ti sheets.

\section{Acknowledgments}

The authors would like to thank the National Science Council of the Republic of China for financially supporting this research under Contract No. NSC 89-2212-E-002-147, which makes the experimental work possible.

\section{References}

[1] P. Jones, W.B. Hutchison, Stress-state dependence of slip in titanium6Al-4V and other H.C.P. metals, Acta Metall. 29 (1981) 951-968.

[2] G. Haicheng, Orientation dependence of slip and twinning in HCP metals, Scripta Mater. 36 (12) (1997) 1383-1386.

[3] M.H. Yoo, Twinning and mechanical behavior of titanium aluminides and other intermetallics, Intermetallics 6 (1998) 597-602.

[4] J.W. Christian, S. Mahajan, Deformation twinning, Prog. Mater. Sci. 39 (1995) 1-157.

[5] S. Ishiyama, S. Hanada, O. Izumi, Orientation dependence of twinning in commercially pure titanium, J. Jpn. Inst. Met. 54 (9) (1990) 976-984.

[6] S.P. Keeler, W.A. Backofen, Plastic instability and fracture in sheets stretched over rigid punches, Trans. Am. Soc. Met. 56 (1963) 25-48.

[7] L. Forcellese, F. Fratini, Gabrielli, F. Micari, The evaluation of springback in 3D stamping and coining processes, J. Mater. Process. Technol. 80-81 (1998) 108-112. 